\title{
What active labor market policy works in a recession?*
}

\author{
by \\ Anders Forslund $^{\#}$, Peter Fredriksson ${ }^{\otimes}$ and Johan Vikström ${ }^{\$}$
}

January 26, 2011

\begin{abstract}
This paper discusses the case for expanding active labor market policy in recession. We find that there is reasonable case for relying more heavily on certain kinds of programs. The argument is tied to the varying size of the lock-in effect in boom and recession. If programs with relatively large lock-in effects should ever be used, they should be used in a downturn. The reason is simply that the cost of forgoing search time is lower in recession. We also provide new evidence on the relative effectiveness of different kinds of programs over the business cycle. In particular we compare an on-the-job training scheme with (traditional) labor market training. We find that labor market training is relatively more effective in recession. This result is consistent with our priors since labor market training features relative large lock-in effects.
\end{abstract}

Keywords: Active labor market policy, business cycle, unemployment JEL-codes: J08, J64, J68

\footnotetext{
* We thank Bertil Holmlund, Clas Olsson, Caroline Hall, Bas van der Klaauw and participants in the CPB/ROA conference on labor market flexibility for helpful comments.

\# Institute for Labour Market Policy Evaluation, P.O. Box 513, SE-751 20 Uppsala, Sweden. E-mail: anders.forslund@ifau.uu.se.

${ }^{\otimes}$ Department of Economics, Stockholm University, SE-106 91 Stockholm, Sweden. E-mail:

peter.fredriksson@ne.su.se.

${ }^{\$}$ Institute for Labour Market Policy Evaluation, P.O. Box 513, SE-751 20 Uppsala, Sweden. E-mail:

johan.vikstrom@ifau.uu.se
} 


\section{Table of contents}

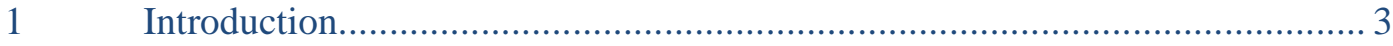

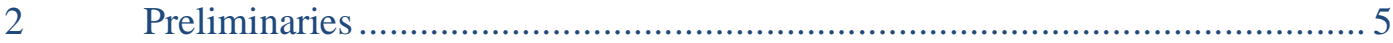

3 Why would treatment effects vary with the cycle? ................................. 8

$4 \quad$ Why should ALMPs vary with the cycle?.................................................. 9

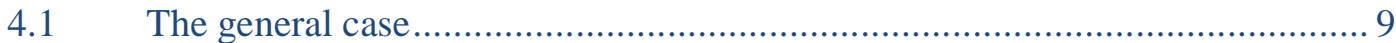

4.2 Relative efficiency of different kind of programs...................................... 10

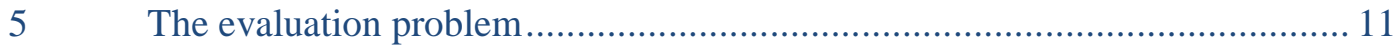

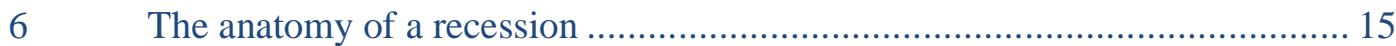

6.1 To what extent do recessions involve structural shocks? .............................. 15

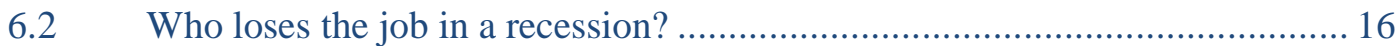

6.3 Program activity and the timing of interventions over the cycle................... 19

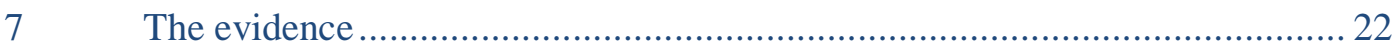

7.1 Direct evidence on the efficacy of ALMPs over the cycle........................... 22

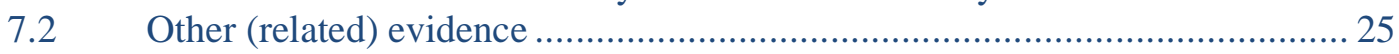

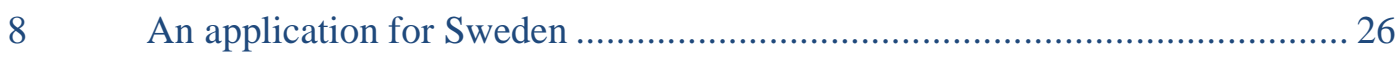

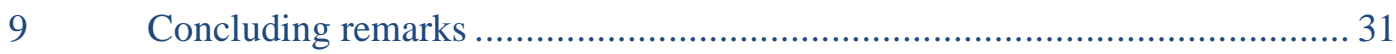

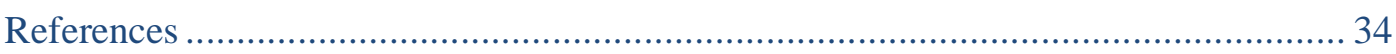




\section{Introduction}

Active labor market policies (ALMPs) have become an integral part of the tool kit for combating unemployment. In 2008, total expenditures on labor market policies amounted to 2.1 percent of GDP in the average OECD country, and 42 percent of the total was devoted to active measures. During 1985-2008 the share of ALMP in total expenditures increased substantially in continental Europe and the UK, stayed constant (and high) in the Nordic countries and was reduced substantially in the US. As a result of these trends, the spending patterns across the OECD countries have become more similar.

Expenditures on ALMPs typically vary with the business cycle, as do any kind of expenditure relating to unemployment. But expenditures on ALMPs relative to overall unemployment expenditures are in fact pro-cyclical: the share devoted to ALMPs increases in a boom. Figure 1 illustrates this fact for a selection of European countries. ${ }^{1}$

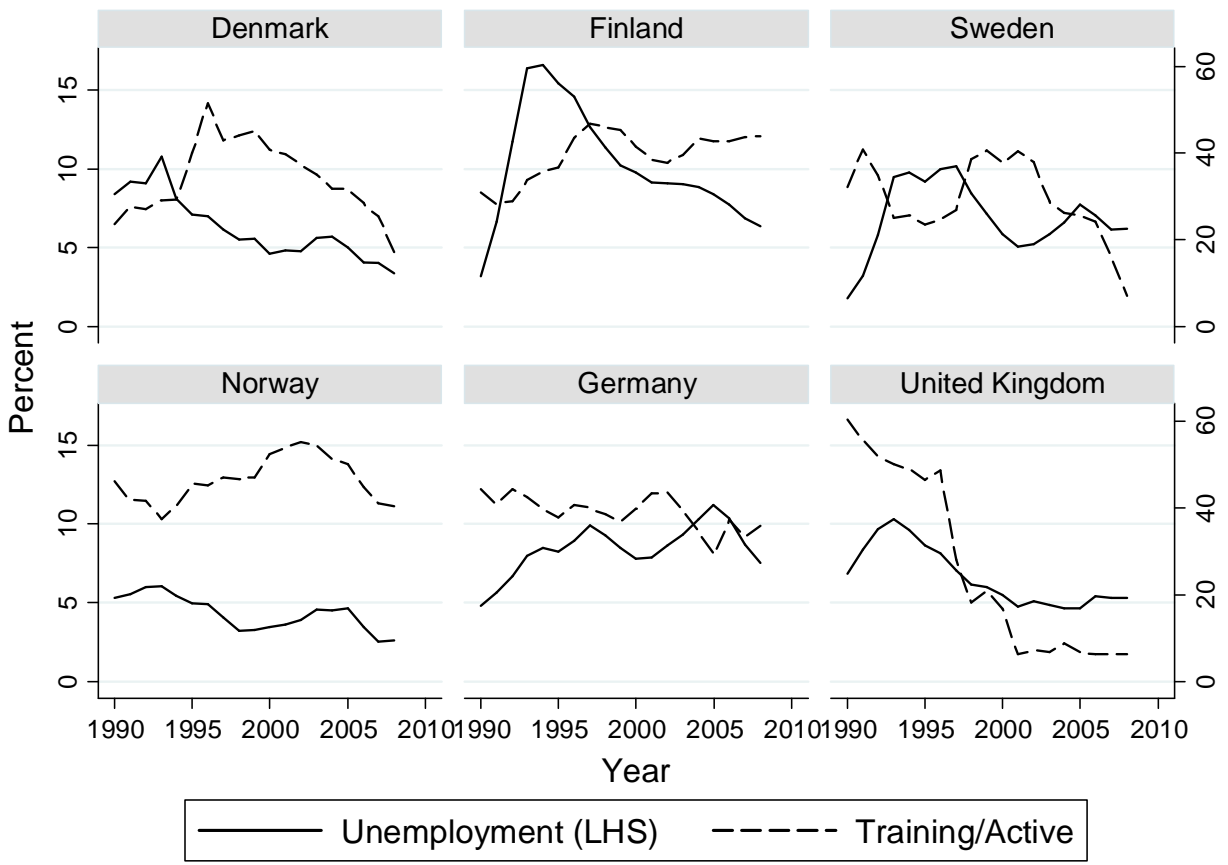

Figure 1: Share of expenditure devoted to ALMP over the business cycle

\footnotetext{
${ }^{1}$ The structure of ALMP expenditure is more difficult to compare across countries for many reasons: all kinds of programs are not available in every country and programs with the same names may have different contents, just to mention two obvious points.
} 
The analysis in this paper provides a discussion of two related questions. First, is there any good reason to vary the spending on ALMP over the cycle? Second, should different programs be relied on more heavily in different phases of the cycle? Or, to bundle both questions into one: What active labor market policy works in a recession?

This is essentially an empirical question. However, the evidence on this important question is extremely scant. So rather than providing concrete policy advice based firmly on the evidence, we try to identify the crucial policy considerations and discuss to what extent the general evidence on the efficacy of ALMPs apply to the question at hand.

The paper proceeds as follows. Section 2 sets the stage by illustrating how we think about ALMP and introducing some concepts that we use later on. Section 3 discusses the positive question of why we might expect ALMP to have different effects across the business cycle. In Section 4 we raise the normative question of why it might be optimal to adjust ALMPs in response to the business cycle and whether certain kinds of ALMPs should be preferable over others. The question of whether the efficacy of a given ALMP varies with the business cycle constitutes a very difficult evaluation problem. In Section 5 we make this evaluation problem more precise.

Remaining sections are devoted to the evidence. We begin by analyzing the nature of a recession in Section 6. Among other things, we characterize the extent to which recessions should be thought of as cyclical or structural shocks and describe the changes of the composition of individuals who lost their jobs in different states of the labor market. We also examine if the composition of participants in ALMP changes with the business cycle. Section 7 turns to the evaluation evidence: We present the evidence that directly relates to the question at hand and discuss what we can infer from other types of evidence.

Since the evidence which is directly relevant is so scant, we devote section 8 to an empirical example. Specifically, we provide evidence on the relative efficacy in boom and recession of two Swedish labor market programs that have both been used fairly extensively: an on-the-job training scheme (arbetspraktik) and vocational training programs (arbetsmarknadsutbildning). To identify the effects of the cycle we use the variation in unemployment rates within local labor markets over time. This enables us 
to abstract from institutional changes affecting both programs, since they are common across regions. This is an improvement relative to the previous literature. Section 9 concludes.

Before turning to the analysis let us mention some limitations. We focus solely on an efficiency argument for expanding (various forms of) ALMPs in a recession. To be more precise, we only discuss whether certain kinds of policies are more beneficial in a recession because they improve the earnings potential of the participating individuals. Thus, we do not discuss purely distributional arguments for using ALMPs (if one is concerned with distributional issues it seems more efficient to use targeted cash transfers instead). Neither do we discuss arguments relating to the possibility that firms may shed too much labor in a recession. Nor do we discuss general equilibrium effects of ALMPs. Yet another omission is that we do not consider "threat effects" or other preprogram effects. Such effects are likely to be less important in recessions, which could motivate a down-sizing of programs in recessions. Finally, we ignore the fact that ALMPs may improve the targeting of UI by making UI benefit receipt conditional on passing the work test implied by program participation. The latter issue is discussed in Fredriksson and Holmlund (2006). The upshot of their analysis is that it is better to use a monitoring scheme or a time-limit on UI benefit rather than a time-consuming labor market program to improve the targeting of UI.

A final remark is that all our own data analysis is based on Swedish data. We do not expect that this has any implications for the generality of the analysis. After all, practically all OECD countries make extensive use of ALMPs today.

\section{Preliminaries}

Before probing deeper into analysis it is useful to make clear what we mean by active labor market policies and to define some concepts that we will use later on.

Unemployment is typically an eligibility condition for ALMP. While this is not true everywhere, it is generally the case that the participants should be searching for a job in order to take part in an active measure. 
We think it is useful to distinguish policies by the different time investments they require on the part of workers. Those requiring a non-negligible time investment we will refer to as "programs". Other policies - for instance job search assistance (JSA) and counseling and monitoring - generally require substantially smaller amounts of time investment.

Programs are analogous to schooling. They are investments in current time and money for a future increase in earnings. The clearest analogy, of course, pertains to labor market training. But we would also like to think of subsidized employment in this way; we think of subsidized employment as investment in on-the-job training which may increase the chances of the participants on the regular (unsubsidized) market.

While pursuing an investment activity you are forgoing something. In this case you are forgoing time that could have been used to search for a regular job, and thereby increasing the probability of finding one.

The effects of treatment are fundamentally different while taking part in the program and after program completion. Figure 2 graphs two examples of hypothetical treatment effects for a given set of individuals. 


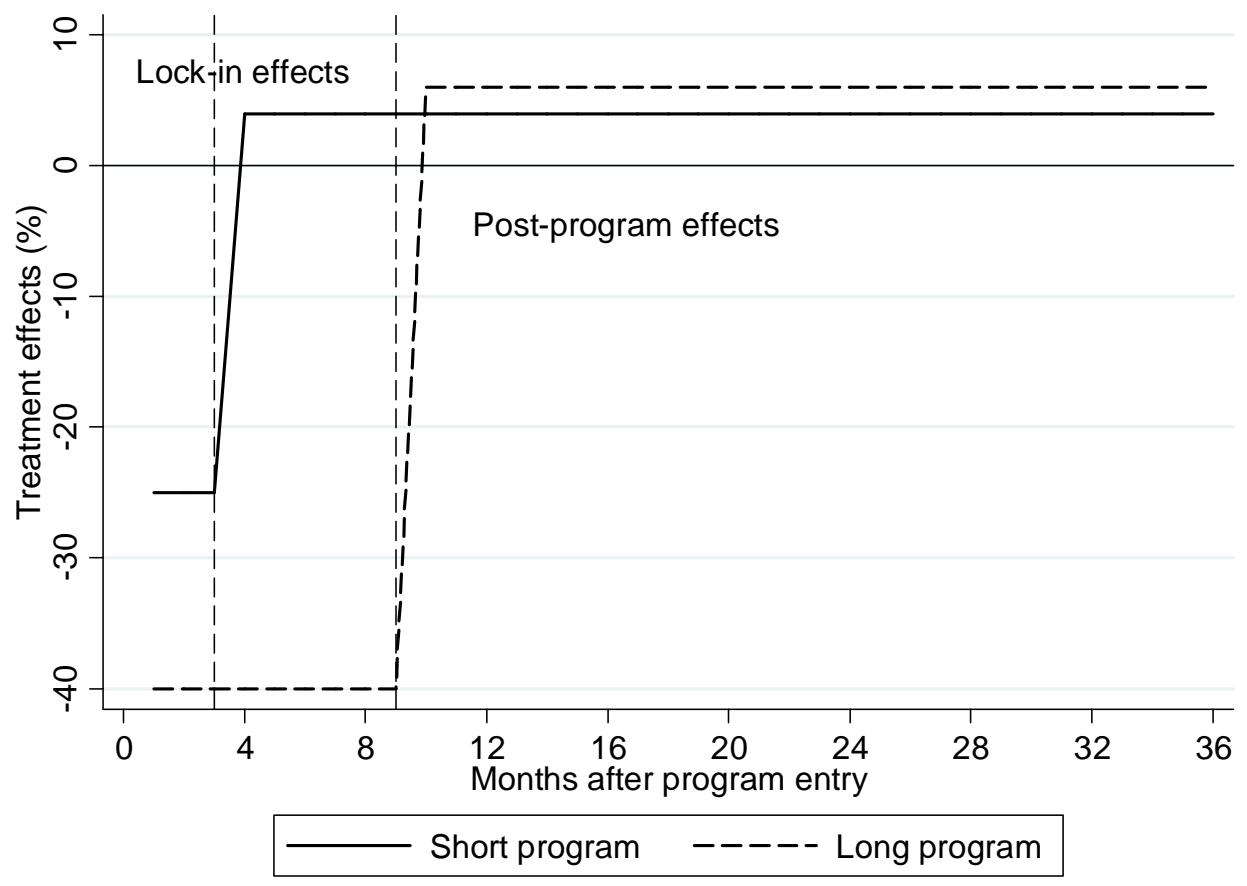

Figure 2: Two hypothetical profiles of treatment effects

The two programs differ in terms of intensity. The intensive program has a planned duration of 9 months while the less intensive one is planned to last for 3 months. The intensity of the program is also reflected in the fact that the intensive one is assumed to have bigger "lock-in" effects than the less intensive one. After program completion, the "post-program" effects are uniformly larger than for the less intensive one.

The first stage of the evaluation is to determine whether the sequence of treatment effects observed after program entry is positive. In a second stage of the analysis, one would like to compare the net benefit to other costs of running the program -- this costbenefit analysis is rarely done, however.

We provide the illustration in Figure 2 to make clear how we think one should estimate the treatment effects. Having said this one should note that this is not how it is always done in the literature. Some researchers only examine the post-program effects, and consider these as the "only" treatment effects. We find this approach strange and it 
answers an ill-posed question (it would be like calculating the return to schooling, ignoring the investment period).

Another reason for showing the example in Figure 2 is that we want to use the terminology we have introduced later on. Therefore, we will use lock-in effects to refer to the treatment effects while taking part in the program, and post-program effects to refer to the treatment effects after program completion.

\section{Why would treatment effects vary with the cycle?}

The clearest argument for why the treatment effects vary with the business cycle relates to the lock-in effects. The lock-in effect should be smaller in a downturn. Intuitively, it is easy to see that if program participants do not search at all, then a downturn only affects the effect of the alternative to treatment (i.e., job search) and thus the lock-in effect is reduced in a recession. More generally, the lock-in effect is smaller in recession if individual search effort and the state of the labor market have complementary effects on the probability of finding a job. ${ }^{2}$

It is more difficult to have a definitive prior regarding the post-program effects. Nevertheless, an intuitive argument is based on "scarring" (i.e. the fact that exposure to unemployment at the time of labor market entry has negative consequences for future earnings; e.g. Ellwood 1982). For those who do not enter the program in a recession, the bad state of the labor market will influence their earnings prospects with certainty. Those who enter a program, however, enter the labor market at some future time point. Chances are that the economy has turned for the better, in which case their employment prospects will not be hurt as much as for those who did not enter treatment.

Other arguments for why average treatment effects vary with the cycle are related to heterogeneous effects. Such treatment heterogeneity may provide an efficiency argument for an expansion of program activity in a recession. Therefore we relegate a discussion of these arguments to the next section.

\footnotetext{
${ }^{2}$ Complementarity simply means that the job offer arrival rate is increasing in search effort holding the business cycle constant. Conversely, a given search effort produces more job offers in a booming labor market than in a depressed labor market.
} 


\section{$4 \quad$ Why should ALMPs vary with the cycle?}

Positive treatment effects are in themselves no argument for subsidizing ALMP - some market failure is required. If the unemployed face credit constraints, it is optimal to provide public insurance. If unemployment implies skill loss, an optimal policy package will typically involve ALMP; see Wunsch (2010). Thus, the combination of credit constraints and skill loss provides an efficiency argument for having ALMPs in general. The questions we raise here is if there is a case for expanding program activity in general during recession and whether certain kinds of policies are more beneficial than others.

\subsection{The general case}

In a labor market where it is optimal to provide public insurance, individual search decisions are distorted. In particular, individual search effort is too low from society's point of view (see Fredriksson and Holmlund 2001). The reason is that there is an "externality" working through the public budget. If everyone would search a bit more, employment would increase; with higher employment, taxes can be lowered which represents a gain for everyone. This general equilibrium effect is not taken into account by the individual agent, and hence represents an externality.

The marginal cost to society of this distortion is likely higher in a booming labor market. The complementary effects of search effort and the state of the labor market on the probability of finding a job are key to this result. If this is the case, then a reduction of search intensity by a given amount decreases employment more in boom than in recession.

Andersen and Svarer (2009) have recently made this point in relation to the question of whether unemployment benefits should be made more generous in a recession. Their answer is "yes" (provided that the balanced budget requirement applies across states of nature), and the reason is precisely the one given above.

As argued earlier, the typical active labor market program involves an investment activity which is completely analogous to investment in education. Since participation in such programs is a time-consuming activity, programs distort the incentives to search, which is also a time-consuming activity (there is ample evidence that there are 
these so-called lock-in effects associated with program participation; see, e.g. van Ours 2004, and evidence on search behavior of program participants in Ackum Agell 1996 or Regnér and Wadensjö 1999). The costs of such distortions are smaller in a recession, which provides one rationale for increasing program activity during a recession.

A crucial issue is to what extent recessions involve structural shocks, rendering worker skills obsolete. If the prevalence of such structural shocks is greater in recession than in boom this is another rationale for increasing program activity during a recession, since programs, at least to some extent, offer retraining to workers.

\subsection{Relative efficiency of different kinds of programs}

Active labor market policy comprises many forms of activities, not just "programs". Some policies do not involve a time investment at all. Moreover, different programs distort search incentives to a varying degree. Therefore intuition suggests that different kinds of ALMPs should be used more extensively in a downturn.

Job search assistance and monitoring of search behavior are two examples of policies that involve marginal investments in time. Job search assistance presumably raises the efficiency of search and monitoring increases the individual return to search for each unit of time that the individual searches for a job. Intuition would suggest that these kinds of ALMPs should be used more extensively in a boom than in a recession.

For the programs involving different extents of time investments, there is arguably a case for using the most intensive programs in a recession. Thus, one would think that training programs which have larger lock-in effects are relatively more efficient in a downturn than programs that distort search incentives to a smaller extent.

Another aspect of program heterogeneity involves the timing of ALMPs. A given program may have differential effects depending on when (in an unemployment spell) an individual enters. A couple of recent papers (Spinnewijn 2010; Wunsch 2010) have analyzed the issue of when the programs should be offered in an unemployment spell. It turns out that the answer depends on the nature of skill loss associated with job loss and unemployment. If job loss in itself involves substantial skill loss relative to the gradual skill loss occurring over the course of unemployment, for example if job loss renders job-specific skills obsolete, then it is better to target individuals early on in the spell. 
One crucial question, then, is whether recessions and displacement have significant structural components. We discuss this question in Section 6.

\section{The evaluation problem}

Treatment effects are likely to vary across individuals, i.e. they are heterogeneous. This heterogeneity presumably applies to the observable as well as the unobservable dimension.

An evaluation amounts to estimating actual and counterfactual outcomes for a given program and a given set of individuals who are eligible for a program. To examine whether the effects of ALMP vary with the business cycle one has to compare treatment effects over time. Such comparisons raise several issues:

1. Is it the same program?

2. Do eligibility or selection rules change?

3. Does the population of eligible individuals change over time?

Regarding the first point, there may be changes in the fine details of the program even though the name of the intervention stays the same. Consider occupational retraining, for instance. At various points in time the Public Employment Service (PES) may decide to offer retraining for different occupations depending on what it thinks is in high demand. Retraining for different occupations implies that there is variation both in the content of the program and presumably also the length of the program. Since both content and length are likely to affect the size of the treatment effect, the effect for the overall program -- occupational retraining -- is likely to vary even though the treatment effect for each individual occupation stays the same.

The second point refers to the overall institutional rules that govern eligibility and selection. For instance, at one point in time a given program may cater only for unemployment insurance recipients, at other points in time the entire population registered at the PES office may be eligible for the program. 
Institutional rules may also affect selection into the program - both self-selection on the part of individuals and PES selection rules. For instance, the introduction of performance criteria may cause PES officers to select different sets of individuals. One example of such performance criteria pertain to labor market training in Sweden. In 1999, a new target was introduced: 3 months after program completion at least 70 percent of the participants should be employed. This reform arguably changed the incentives in favor of enrolling individuals with relatively good employment prospects with and without the program. Another example (from Sweden) of changes in institutional rules pertains to the relationship between UI eligibility and program participation. Prior to 2001, program participation could be used to renew UI eligibility. During 2001 this opportunity was abolished. Such changes clearly affects incentives and, hence, the selection of individuals into the program.

Even if the first and second points are not a concern, the population of eligibles (who are usually the unemployed) may change over time. This will affect the size of the average treatment effects if there is treatment heterogeneity. Treatment heterogeneity may occur in the observed and the unobserved dimension. Figure 3 illustrates a hypothetical example. It graphs the distribution of treatment effects for individuals who are unemployed in boom (dashed) and recession (solid). In Figure 3 we have assumed that in a recession the distribution is skewed towards those who have less to gain from the program. ${ }^{3}$ This will give the impression of a smaller average treatment effect in recession, even though there is no variation in the effects of treatment at the individual level.

\footnotetext{
${ }^{3}$ This is consistent with the results in de Luna et al. (2008), where it was found that the treatment effect of training programs was decreasing in the level of education. In Section 6.2 we show that job losers in recession are drawn from the higher end of the wage distribution to a greater extent than job losers in boom, so that job losers in terms of observed and unobserved characteristics are drawn from a higher end of the distribution in depression than in boom.
} 


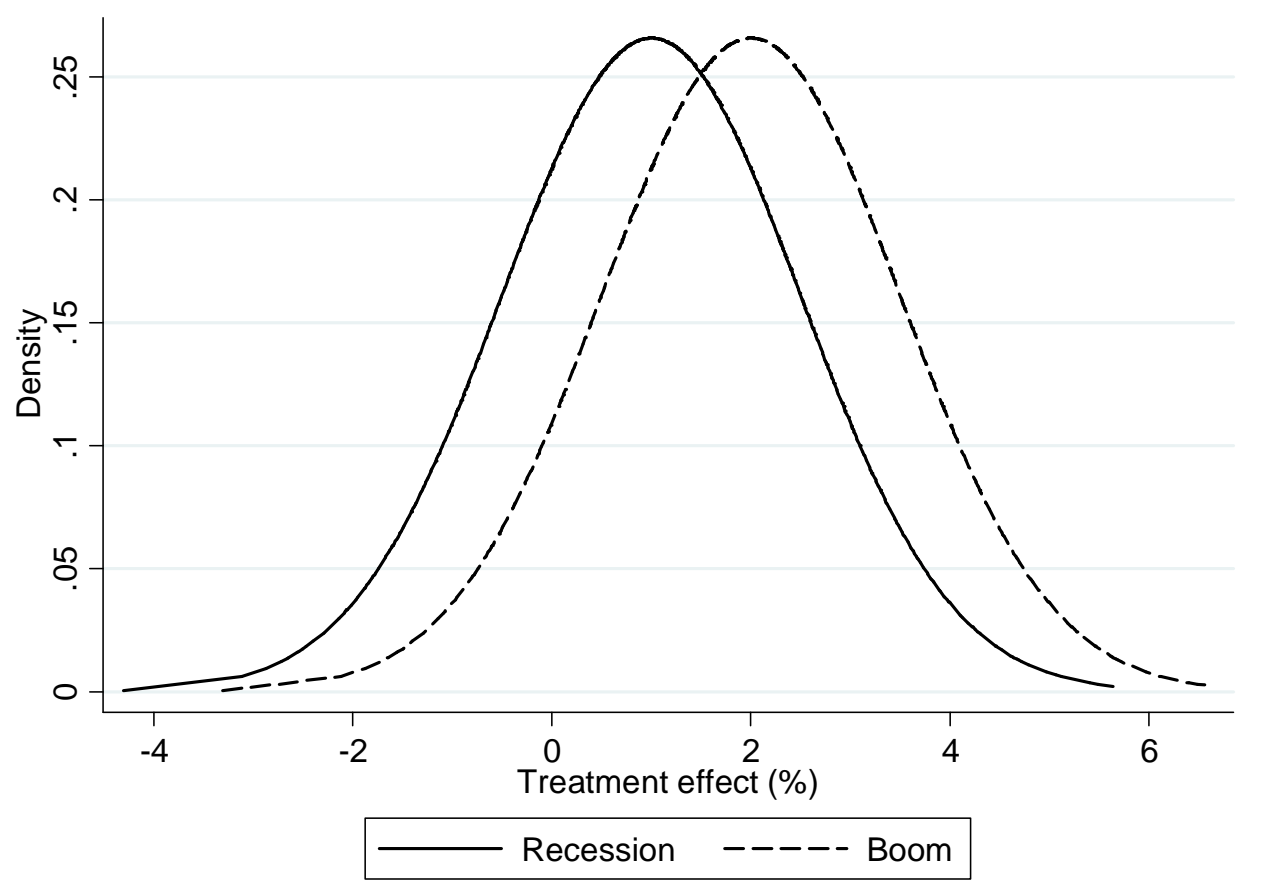

Figure 3: The distribution of treatment effects in boom and recession

To make matters even more difficult, there may be true (as opposed to spurious) duration dependence. With duration dependence unemployment has a causal effect on the unemployed individuals, so individuals become dissimilar in terms of job chances even though they may have been identical at the start of an unemployment spell. This complicates the evaluation problem if there is variation in the duration until program start. If treatment effects vary systematically with the timing of the intervention, the estimates may differ across the cycle even though there is really no difference.

It is useful to ask the question: Would a series of experiments (or quasi-experiments) run at different points of the business cycle help us solve the evaluation problem? The short answer is that they would, if treatment effects are homogenous. But if there is treatment heterogeneity along the lines shown in Figure 3, we have to impose additional assumptions in order to solve the evaluation problem.

To see this, note that experiments provide internally valid estimates, i.e., they estimate the mean causal impact for the population studied. With treatment hetero- 
geneity, however, the results do not extend to another population, i.e., they are not externally valid. If the observed and unobserved characteristics of the eligible population vary with the state of the labor market, it is, in general, not possible to extrapolate the results from one time point to another.

When would the variation in experimental estimates across the cycle have a causal interpretation? One would have to assume that treatment heterogeneity is only in the observed dimension. Under this assumption it is straightforward to adjust the estimates to take the variation in the distribution of observed characteristics across the state of the business cycle into account. But in the general case with treatment heterogeneity also in the unobserved dimension, the adjustment in terms of observed characteristics only provide unbiased estimates under a "selection-on-observables" assumption (this assumption is sometimes referred to as the conditional independence assumption). This assumption effectively says that it is sufficient to control for observed characteristics to obtain unbiased estimates of the treatment effect.

But if you are forced to make a selection-on-observables assumption to interpret the variation in the experimental estimates across the states of the business cycle, it seems equally valid (and certainly more feasible) to base the entire analysis on this assumption. In short, the value added of experiments is more limited than usual for the question at hand.

Whether the selection on observables assumption is credible or not depends crucially on the richness of the information in the data used for the analysis. In recent years, administrative data sets containing, e.g., earnings and unemployment histories prior to program participation have become available. The availability of these data sets seems to have reduced the potential bias associated with the selection-on-observables assumption. Indeed, a recent meta analysis by Card et al. (2009) suggests that the qualitative conclusions do not differ systematically between experimental and non-experimental approaches. 


\section{The anatomy of a recession}

Recessions are not just cyclical shocks. They may involve a significant amount of structural adjustment. If recessions involve more structural adjustment than the secular adjustment going on in a normal state of the labor market, then this has an effect on the optimal timing of ALMPs as argued above.

A further issue is that different kinds of individuals are likely to lose their job in a recession than in other labor market states. This has (at least) two implications. First, if different kinds of individuals lose their jobs in a recession, this substantially complicates the evaluation problem; the reason is that individuals differ in a number of respects, not only in the dimensions that we can typically observe in the data. Second, if there are heterogeneous effects of ALMPs, and different individuals become unemployed in a recession, this has implications for the appropriate mix of ALMPs.

In this section we use Swedish data do address these issues.

\subsection{To what extent do recessions involve structural shocks?}

We have used the OECD composite leading indicator to identify Swedish business cycle peaks and troughs in the 1990s and 2000s. Looking at employment by industry, we have then classified employment changes as cyclical or structural depending on employment changes before and after peaks or troughs. We consider employment changes where employment either grows or contracts both before and after a turning point as employment in industries with structural change; see Groshen and Potter (2003) for a discussion of the methods used. Using this methodology, we get the results presented in Table 1. 
Table 1: Share (\%) of total employment in sectors with structural change

\begin{tabular}{lcc}
\hline & \multicolumn{2}{c}{ Beginning of 1990s } \\
(Date (month) of peak/trough) & $\begin{array}{c}\text { Beginning of 2000s } \\
\text { (Date (month) of peak/trough) }\end{array}$ \\
\hline \multirow{3}{*}{ Boom } & 40.6 & 75.5 \\
Recession & $(1990: 2)$ & $(2000: 9)$ \\
& 50.8 & 32.7 \\
& $(1993: 4)$ & $(2003: 2)$ \\
\hline
\end{tabular}

Note: Computations based on industry employment according the Labor Force Surveys (44 industries). The employment growth rate in each industry is measured relative to the national average growth rate.

According to Table 1, the recession in the beginning of the 1990s involved more structural adjustment than the boom that preceded the recession. However, for the peaks and troughs occurring in the beginning of the 2000s, the opposite is true. On average, there thus seems to be about as much structural change in boom as in recession. At least there are no clear indications that structural change is concentrated to recessions.

The main message of Table 1 is that it is difficult ex ante to determine from the business cycle position whether aggregate job losses are cyclical or structural. The targeting of labor market programs should arguably be based on predicted individual risks instead.

\subsection{Who loses the job in a recession?}

Here the purpose is to characterize the skills of individuals who lose their jobs in a recession. We follow Juhn et al. (1991) in using wages as a summary measure of skills. We further decompose wages in a part explained by standard observed characteristics and an unexplained part.

We have chosen the years 1992 to represent recession and 2005 for boom. ${ }^{4}$ Hence, we identify individuals who were employed in 1991 and entered unemployment in 1992 as individuals who lost their job in recession; ${ }^{5}$ those who were employed in 2004 and

\footnotetext{
${ }^{4}$ One may discuss the choice of 2005 to represent a boom year. Nevertheless we think this choice is entirely innocuous. The important point is that the state of the business cycle is much better in 2005 than in 1992. According to the OECD composite leading indicator, a sustained business cycle expansion started in February 2005 which peaked in January 2008. For the analysis conducted here, 2006 or 2007 would perhaps have been more natural choices. The reason for choosing 2005 rather than 2006 or 2007 is that we characterize selection into labor market programs during boom and recession later on. For that analysis the change in government in 2006 constitutes a problem. Along with the change of government came a major restructuring of labor market policy. Therefore, we think it is better to use 2005 rather than the later years since otherwise the analysis may be contaminated by the "structural change" of ALMP.

${ }^{5}$ Data on unemployment entry come from the registers of the National Labor Market Board. It should be clear that individuals may have left employment for other reasons than having been laid off.
} 
entered unemployment during 2005 lost their job in a boom. The question we are asking is whether the distributions of observed and unobserved skills are different over periods of boom and recession.

Figure 4 plots the density of the job loss distribution by age and wage percentile for men, while Figure 5 presents an analogous plot for women. The solid lines relate the job loss to skills in recession, while the dashed lines pertain to boom.

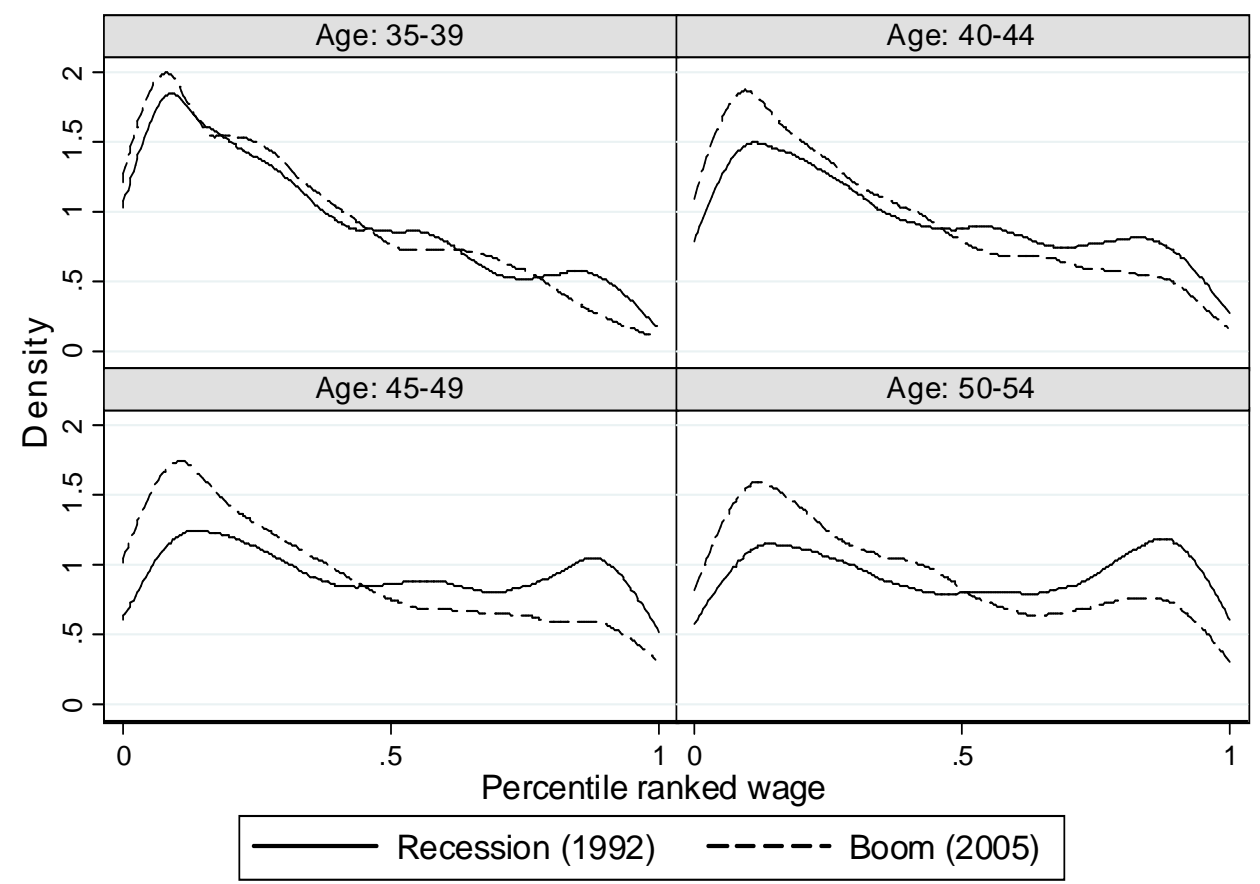

Figure 4: Job loss by wage percentile in boom and recession, men

Notes: Calculations based on the unemployment register and wage register (strukturlönestatistiken).

Job losers in recession are drawn from the higher end of the wage distribution to a greater extent than job losers in boom. ${ }^{6}$ This pattern is most pronounced for older men. At lower ages, the picture is probably distorted by the fact that employment security legislation (last in - first out) interacts with age and the business cycle. The pattern that individuals at the higher end of the wage distribution are hit relatively harder is less

\footnotetext{
${ }^{6}$ Interestingly, Mueller (2010) presents similar evidence for the U.S.
} 
clear-cut for females. A possible explanation is that this reflects the larger employment share for females in the public sector, but due to data limitations, we have not been able to examine this thoroughly.

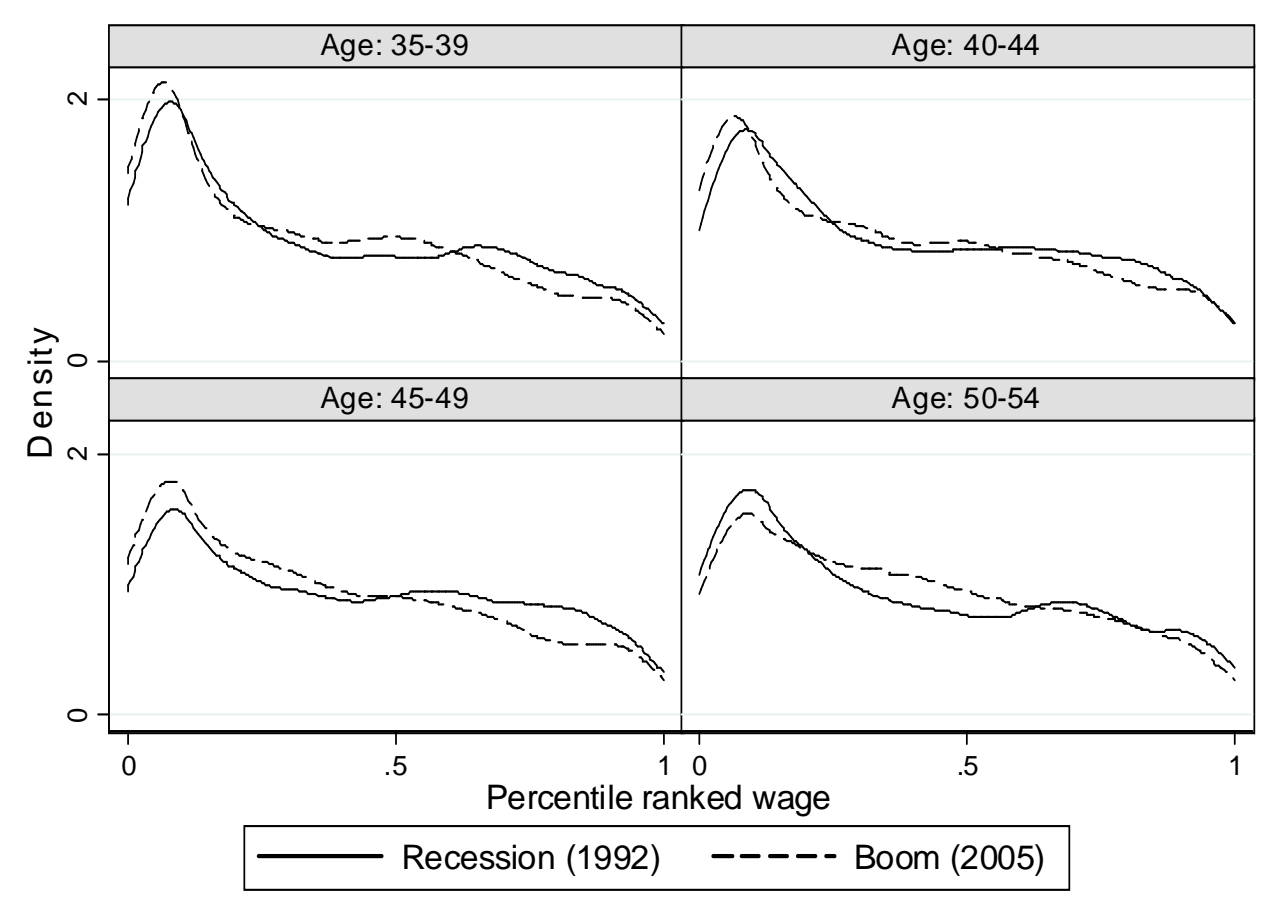

Figure 5: Job loss by wage percentile in boom and recession, women

Notes: Calculations based on the unemployment register and wage register (strukturlönestatistiken).

When decomposing skills into observed and unobserved ones (not shown here), we note that much of the pattern for men is driven by the residual wage distribution, i.e., by unobserved skills. ${ }^{7}$ This may be a warning against too much reliance on estimated treatment effects using models where identification relies on selection on observed characteristics (such as, e.g., matching models) - characteristics of job losers change over the cycle and a non-negligible part of this is driven by unobserved characteristics. ${ }^{8}$

\footnotetext{
${ }^{7}$ As the measure of observed skills we use predicted wages. Predicted wages are generated from a standard wage regression (run separately by gender), where log wages are explained by a fourth order polynomial in age, education, immigrant status, and years since migration.

${ }^{8}$ Perhaps one should not be overly alarmed. Using the typical register data set one can condition the analysis on wages and earnings prior to program entry.
} 


\subsection{Program activity and the timing of interventions over the cycle}

Here we examine two questions: The first question is whether the characteristics of program participants change with the cycle; the second question is how the probability of entering a program varies by elapsed duration over the cycle.

Regarding the first question, there are several reasons to suspect that the characteristics of participants vary with the cycle. First of all, the skill composition of the eligible population changes in a recession, as demonstrated in the previous section. Second, if there are capacity constraints, recessions imply more competition for the available program slots.

Skedinger (2010) examined if the skill composition of program participants varies with the cycle. He regressed, inter alia, the share of low-educated in programs on unemployment, holding constant the share of low-educated among all individuals who are at risk of participating in a program. ${ }^{9} \mathrm{He}$ performed the analysis on monthly aggregate data including seasonal fixed effects in the analysis. Table 2 reproduces a sub-set of the results from Skedinger (2010).

Table 2: Cyclical variation in the relative risk for low-educated of participating in ALMP

\begin{tabular}{|c|c|c|c|c|}
\hline \multicolumn{5}{|c|}{ Dependent variable: Share low-ed. in programs } \\
\hline & Overall & LMT & JSA & Subsidized jobs \\
\hline Unemployment & $\begin{array}{l}-0.86 \\
(4.68)\end{array}$ & $\begin{array}{l}-0.89 \\
(3.94)\end{array}$ & $\begin{array}{l}-1.52 \\
(3.11)\end{array}$ & $\begin{array}{c}0.66 \\
(2.77)\end{array}$ \\
\hline
\end{tabular}

Note: Monthly data 1996:01-2009:11. The regressions include seasonal FE:s and the share low-ed. among the eligible. T-ratios in parentheses.

Source: Skedinger (2010).

The first column of Table 2 illustrates that if the unemployment rate increases by 1 percentage point, the relative risk that the low-educated (those with compulsory education or less) participates in a program decreases by -0.86 percentage points. When decomposing the overall effect into separate effects for different kind of programs, he found that this conclusion applied to labor market training (LMT; see col. 2) and job

\footnotetext{
${ }^{9}$ Since being recorded as unemployed is a pre-condition for partaking in a program, he controlled for the share of low-educated in the unemployment register.
} 
search assistance (JSA; see col. 3) but not for subsidized jobs (col. 4). Thus the increasing number of high-educated in a recession to some extent crowds out the loweducated. Lechner and Wunsch (2009) presented similar evidence for Germany.

Skedinger (2010) conducted the same analysis for other characteristics. In short he found that youths are more likely to participate in a program during recession, that the participation rates of refugee immigrants are unrelated to the cycle, and that the relative risk of participating in a program decreases in a recession for individuals with: (i) a work impairment; and (ii) more than 2 years of unemployment.

We have used micro data to revisit this issue. The advantage of using the micro data is that we can control for a (potentially large) number of characteristics simultaneously to isolate the unique contribution from each of the characteristics. The results of Cox regressions for hazards to all programs in boom and recession are shown in Table $3{ }^{10}$

${ }^{10}$ The Cox regression models the flow (hazard rate) to programs as the product of a baseline hazard $\left(h_{0}(t)\right)$ and a part that depends on characteristics $(X): h_{i}(t)=h_{0}(t) e^{X \beta}$, where $\beta$ denotes (a vector of) parameters to be estimated. An estimate of -0.06 on (say) immigrant status means that it is 6 percent less likely that an immigrant will enter a program (per unit time) relative to an individual born in Sweden. Note, that this interpretation is based on the common practice of approximating relative changes with log changes. For sizable estimates, one should calculate the relative change as: $e^{\beta}-1$. 
Table 3: Determinants of ALMP participation in boom and recession

\begin{tabular}{|c|c|c|c|}
\hline VARIABLES & $\begin{array}{c}(1) \\
\text { Recession (1992) } \\
\end{array}$ & $\begin{array}{c}(2) \\
\text { Boom (2005) } \\
\end{array}$ & $\begin{array}{c}(3) \\
\text { Difference: (1)-(2) }\end{array}$ \\
\hline Less than upper-secondary ed. & $\begin{array}{l}-0.11 * * \\
(0.0053)\end{array}$ & $\begin{array}{c}0.0051 \\
(0.0087)\end{array}$ & $\begin{array}{c}-0.11 * * \\
(0.010)\end{array}$ \\
\hline Immigrant & $\begin{array}{l}-0.061 * * \\
(0.0065)\end{array}$ & $\begin{array}{l}-0.0042 \\
(0.0082)\end{array}$ & $\begin{array}{c}-0.057 * * \\
(0.010)\end{array}$ \\
\hline Age $20-29$ & $\begin{array}{c}0.37 * * \\
(0.0051)\end{array}$ & $\begin{array}{c}0.13 * * \\
(0.0077)\end{array}$ & $\begin{array}{c}0.24 * * \\
(0.0092)\end{array}$ \\
\hline Age $55+$ & $\begin{array}{c}-0.87 * * \\
(0.014)\end{array}$ & $\begin{array}{c}-0.28 * * \\
(0.015)\end{array}$ & $\begin{array}{c}-0.59 * * \\
(0.020)\end{array}$ \\
\hline Child under 10 & $\begin{array}{l}-0.062 * * \\
(0.0054)\end{array}$ & $\begin{array}{l}0.046 * * \\
(0.0084)\end{array}$ & $\begin{array}{c}-0.11 * * \\
(0.010)\end{array}$ \\
\hline Male & $\begin{array}{c}-0.072 * * \\
(0.0046)\end{array}$ & $\begin{array}{c}0.13 * * \\
(0.0071)\end{array}$ & $\begin{array}{l}-0.20 * * \\
(0.0084)\end{array}$ \\
\hline Married & $\begin{array}{c}-0.033 * * \\
(0.0059)\end{array}$ & $\begin{array}{l}0.00086 \\
(0.0088)\end{array}$ & $\begin{array}{c}-0.033 * * \\
(0.011)\end{array}$ \\
\hline Outside big cities & $\begin{array}{c}0.40 * * \\
(0.0066)\end{array}$ & $\begin{array}{l}0.63 * * \\
(0.011)\end{array}$ & $\begin{array}{c}-0.23 * * \\
(0.013)\end{array}$ \\
\hline Observations & 572,716 & 522,714 & $1,095,430$ \\
\hline
\end{tabular}

Notes: The results are generated using Cox regressions on data from the Swedish unemployment register. The analysis only includes individuals ages $20-60$. Standard errors in parentheses: $* * \mathrm{p}<0.01, * \mathrm{p}<0.05$.

By and large, the micro data convey the same message as the analysis in Skedinger (2010); the only substantive difference pertains to immigrants. On the one hand, the program hazards are significantly lower in recessions for: those with less than high school education, immigrants, and individuals aged 55-60 (relative to individuals aged $30-44)$. On the other hand, the probability of entering a program is higher in recession for young persons. To take an example of the magnitudes involved, the estimates indicate that the program hazard for those with less than upper-secondary education is (roughly) 11 percent lower in recession than in boom.

In Figure 6 we present cumulative distribution functions (the CDFs) for time until program entry in boom (2005) and recession (1992) for those who actually enter a program. Since the probability of having started the program before a certain time point is always higher in boom than in recession, the figure implies that individuals enter programs earlier in an unemployment spell in a good state of the business cycle. 


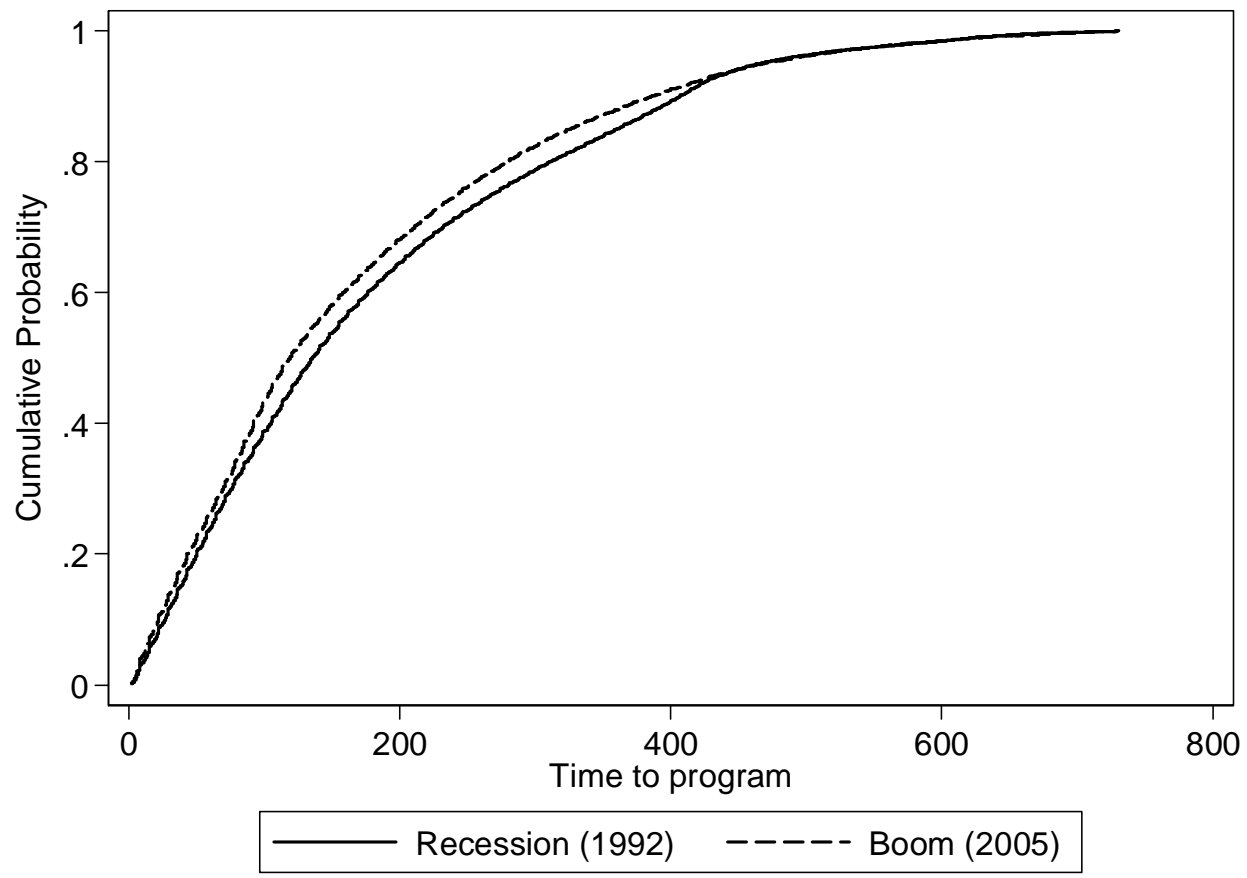

Figure 6: CDF for time to program in a boom and in a recession

Note: Calculations based on the Swedish unemployment register using individuals aged 20-60.

\section{The evidence}

To what extent do the effects of ALMP vary with the business cycle? As we have emphasized repeatedly, there is not so much evidence that directly pertains to the question we are interested in. Notice that the policy-relevant question relates to the state of the labor market at the time of program start. A few papers (Johansson 2001; Raaum et al. 2002) have examined whether the state of the labor market at the time of measuring outcomes matters. Although this might be an interesting factual, it is less clear why policy makers should be concerned with that question.

\subsection{Direct evidence on the efficacy of ALMPs over the cycle}

Lechner and Wunsch (2009) is the only paper that has directly addressed the question we are interested in. The lack of research on this issue is presumably not driven by lack of interest - the question is certainly highly policy relevant. Rather we think that the lack of evidence is driven by the fact that this is a hard evaluation problem (see section 
5) and the fact that extraordinary data are required; in particular, the time dimension of the data should cover both boom and recession. Given that Lecher and Wunsch (2009) is the only paper available, we spend some time on their paper.

Lechner and Wunsch considered training in (West) Germany. The treated population may have entered training at some time point between 1986 and 1995. Labor market outcomes are observed until 2003. Their analysis is based on a selection-on-observables assumption (there is presumably no other alternative).

They estimate short-run program effects (outcomes observed 6 months after program entry) and long-run effects (outcomes observed 8 years after program entry). The shortrun effects primarily capture the lock-in effects of program participation.

Lechner and Wunsch found that, on average, program participation reduced the employment probability by 15 percentage points in the short run and increased the employment probability by 10 percentage points in the long run. Cumulated over the 8 years that outcomes can be observed (which is arguably the most relevant metric), the estimates imply a relative increase in months of employment by 5 percent.

The main point of the Lechner and Wunsch (2009) paper is, however, to correlate the estimated treatment effects with the unemployment rate at program entry. Table 4 reproduces their baseline results.

Table 4: Correlations between program effects and unemployment rate at program entry

Dependent variable: Programs effects (Outcome: employment)

Correlation with unemployment at program entry

Short-run effect (6 mths.) $\quad 0.25^{*}$

$\begin{array}{ll}\text { Long-run effect (8 yrs.) } & 0.31 * *\end{array}$

Note: Based on Lechner \& Wunsch (2009), Table 2. * = significant at $5 \%$ level; ** = significant at $1 \%$ level

As shown in Table 4, their analysis suggests that when unemployment at the time of program entry is high: (i) lock-in effects are less negative; and (ii) long-run effects are more positive. 
Table 4 reports the baseline results of Lechner and Wunsch (2009). These baseline estimates are potentially plagued by (at least) two problems. First, the skill composition of program participants changes with the cycle; in Germany, participants tend to be more positively selected in a downturn. Second, "training" is a heterogeneous group of programs; the composition may change over the cycle as might the planned duration of a given program. Lechner and Wunsch found that these two problems raise no concerns. The correlations with the unemployment rate at program entry do no change much when the characteristics of the participants and the composition of training programs are held constant.

What are the caveats to Lechner and Wunsch (2009)? One obvious caveat is that this is only one study of a single program for a single country. Of course, this is too little empirical evidence to base definitive conclusions on. Nevertheless, we see no obvious reason for thinking that the correlation between unemployment and the effects of training in Germany should be different from other countries. However, we are reluctant to extrapolate from training to other forms of ALMP. The best case for expanding ALMP is probably labor market training.

But there are also aspects of the Lechner and Wunsch study that could be improved upon. A maintained assumption in their study is that there are no changes in the institutional set-up for training during 1986-95. But this is argued rather than shown, and it is not possible for us to assess whether the assumption is credible. In this respect, it would have been preferable to examine if treatment effects vary systematically with changes in unemployment within regions over time. The virtue of this approach is that one can abstract from institutional changes since they are common across regions (at least in centralized systems such as the Nordic ones).

Another maintained assumption is that there is no (or irrelevant) variation in the duration until program start. Programs on average start later in a recession (see the evidence in Section 6.3). Because of capacity constraints, there is some "weeding-out" of the unemployment pool. This is a concern since duration dependence implies that individuals become different even though they were identical to begin with. It should be straightforward to adjust for the differences in the duration until program start across the 
cycle; after all the duration until program start is observed (see Fredriksson and Johansson 2008).

In principle one could also raise concerns about the selection-on-observables assumption. This critique, however, seems rather moot since there is no other alternative in practice (see Section 5).

\subsection{Other (related) evidence}

Given the lack of directly relevant evidence, it is reasonable to look for other evidence that can shed light on the issue. A meta-study by Kluve (2010) indicates that the average rate of unemployment during the program spell does not interact significantly with overall program effectiveness. However, there is a positive interaction with the effect of labor market training, suggesting that labor market training is more effective in a downturn. Since, a meta-analysis just pools together different estimates from different studies it is not possible to adjust for changes in the composition of participants and programs over the cycle.

A few papers correlate treatment effects with unemployment at the time of measuring outcomes. The paper by Raaum et al (2002), for instance, found worse effects of labor market training when unemployment is high. But this finding has unclear implications for policy design.

A relevant issue is whether there are more individuals who would benefit from a program in a slump. This relates to the question of heterogeneous treatment effects. But there is fairly limited systematic evidence on such heterogeneous effects. A general conclusion, however, is that programs do not benefit youths to the same extent as older age categories (see Card et al. 2009). Also there is some limited evidence that loweducated and immigrants have more to gain from training (e.g., de Luna et al. 2008). Taken at face value, these two results suggest that the variation in the characteristics of program participants that we observe over the cycle in Sweden is not optimal.

If the rate of skill obsolescence is higher in recession, there are indeed more individuals who benefit from a program in a downturn. On basis of the evidence we presented in Section 6.1, there is no such general pattern.

Finally, another kind of related evidence is presented in Schmieder et al. (2009), where it is found that the changes in the generosity of unemployment insurance have 
very similar effects in boom and recession. This may indicate that we should not expect very large differences between locking-in effects in different phases of the cycle.

\section{An application for Sweden}

Here we provide new evidence on the effects of ALMPs over the business cycle. More specifically, we compare the effects of a Swedish on-the-job training scheme (arbetspraktik) to the effects of labor market training (LMT) over the cycle. The on-thejob training scheme, which we will refer to as work practice (WP), has been used fairly extensively in both boom and recession. In our most sophisticated regressions, we identify the effects of the cycle using the variation within local labor markets over time and adjust the estimates for differences in the timing of the start of the program. We thus address two points of criticism that can be levied on the study by Lechner and Wunsch (2009).

There are three main reasons for comparing treatment effects of two programs (instead of estimating the treatment effect of one program relative to non-participation). First, we believe that selection on observed characteristics (or conditional independence) is a more credible assumption when comparing the two programs. Second, by comparing two programs we take account of factors affecting all programs that correlate with the regional unemployment rate. Third, the relative comparison answers the highly policy relevant question: What kind of program - the on-the-job training scheme or the labor market training scheme - is more effective in a downturn?

We first perform one-to-one propensity score matching of treated $(W P)$ and comparison individuals (LMT) on year of inflow and duration of unemployment spell before program entry as well as a battery of covariates. ${ }^{11}$ We use individuals aged $25-$ 55 and consider programs that start within the first year of unemployment. ${ }^{12}$ Under conditional independence we can use the matched treatment and control group to make a straightforward comparison of the two programs. To this end we estimate a Cox

\footnotetext{
${ }^{11}$ The covariates include gender, age, level of education, country of origin, if the unemployed is willing to accept part-time employment, citizenship, region and previous unemployment (number of days and number of unemployment spells during each of the four years before the start of the unemployment spell.)

12 We consider open unemployment and time in any labor market program as unemployment. Temporary employment and part-time employment that last more than 30 days are considered as employment.
} 
regression model where we allow the treatment effects to vary by time since program entry (100 days). ${ }^{13}$ Column (1) in Table 5 presents the estimates from this exercise. The idea is that any locking-in effects will be occurring mainly during the first 100 days, while any post-program effects will mainly occur after the first 100 days. If so, the relative size of the locking-in effects will be captured by the estimate of the main effect (denoted WP), while the relative size of the post-program effects will be captured by the sum of the coefficients on the main effect and the interaction term $(W P \times T>100)$.

Table 5: The efficiency of Work Practice $(W P)$ relative to Labor Market Training

\begin{tabular}{lccccc}
\hline VARIABLES & $\begin{array}{c}(1) \\
\text { General effect }\end{array}$ & $\begin{array}{c}(2) \\
+ \text { by cycle }\end{array}$ & $\begin{array}{c}(3) \\
+ \text { by year and } \\
\text { county }\end{array}$ & $\begin{array}{c}(4) \\
\text { +by time to } \\
\text { program start }\end{array}$ & $\begin{array}{c}(5) \\
\text { + by individual } \\
\text { characteristic }\end{array}$ \\
\hline$W P$ & $0.25^{* *}$ & $0.25^{* *}$ & $0.18^{* *}$ & $0.14^{* *}$ & $0.29^{* *}$ \\
$W P \times T>100$ & $(0.012)$ & $(0.012)$ & $(0.043)$ & $(0.046)$ & $(0.090)$ \\
& $-0.45^{* *}$ & $-0.45^{* *}$ & -0.082 & $-0.10^{*}$ & $-0.35^{* *}$ \\
$W P \times($ regional $u)$ & $(0.014)$ & $(0.014)$ & $(0.049)$ & $(0.053)$ & $(0.099)$ \\
$W P \times T>100 \times$ & & $-0.015^{* *}$ & -0.0038 & $-0.029^{*}$ & $-0.030^{*}$ \\
$($ regional $u)$ & & $(0.0042)$ & $(0.012)$ & $(0.013)$ & $(0.013)$ \\
& & -0.0027 & 0.016 & 0.0086 & 0.0053 \\
Observations & & $(0.0054)$ & $(0.016)$ & $(0.016)$ & $(0.016)$ \\
\hline
\end{tabular}

Note: The estimates are based on Swedish data during 1999-2005. Regional unemployment is measured at the county level and corresponds to the unemployment rate during the month when the program started. Regional unemployment rates are deviations from the mean unemployment level during the observation period, so that main effects can be interpreted as the mean effect at mean unemployment. Standard errors in parentheses: $* * \mathrm{p}<0.01, * \mathrm{p}<0.05$

Using these two estimates one can also get a sense of the relative size of the total effect (the sum of lock-in effects and post-program effects) over some time horizon. The two estimates imply that training outperforms work practice in the longer run, because the post-program effect will eventually outweigh the estimated lock-in effect. Indeed, the survivor functions implied by column (1) suggest that the probability of remaining in unemployment is lower for $L M T$ than WP for evaluation horizons that extend beyond 7 months (218 days) after program entry. This is shown in Figure 7, which plots the relative probability of leaving unemployment for employment (computed as the difference between the survivor functions for the two programs). Alternatively, one can

\footnotetext{
${ }^{13}$ We present Cox regression estimates since they allow us to summarize the relative effects in two coefficients. We have also estimated the relative effects on the survival rates. It produces similar patterns.
} 
calculate the relative effect on unemployment duration: $L M T$ reduces unemployment duration for evaluation horizons beyond 15 months (464 days) after program entry. ${ }^{14}$

The estimates in column (1) correspond well to previous Swedish work on related issues. Forslund and Nordström Skans (2006) estimated relative treatment effects of two programs for young participants, and found significantly better long-run effects of training programs along a number of labor market outcomes. Arbetsförmedlingen (2010a) presented estimated treatment effects for both programs. They found that training had a more favorable effect on the outflow from unemployment to work, over a one year horizon.

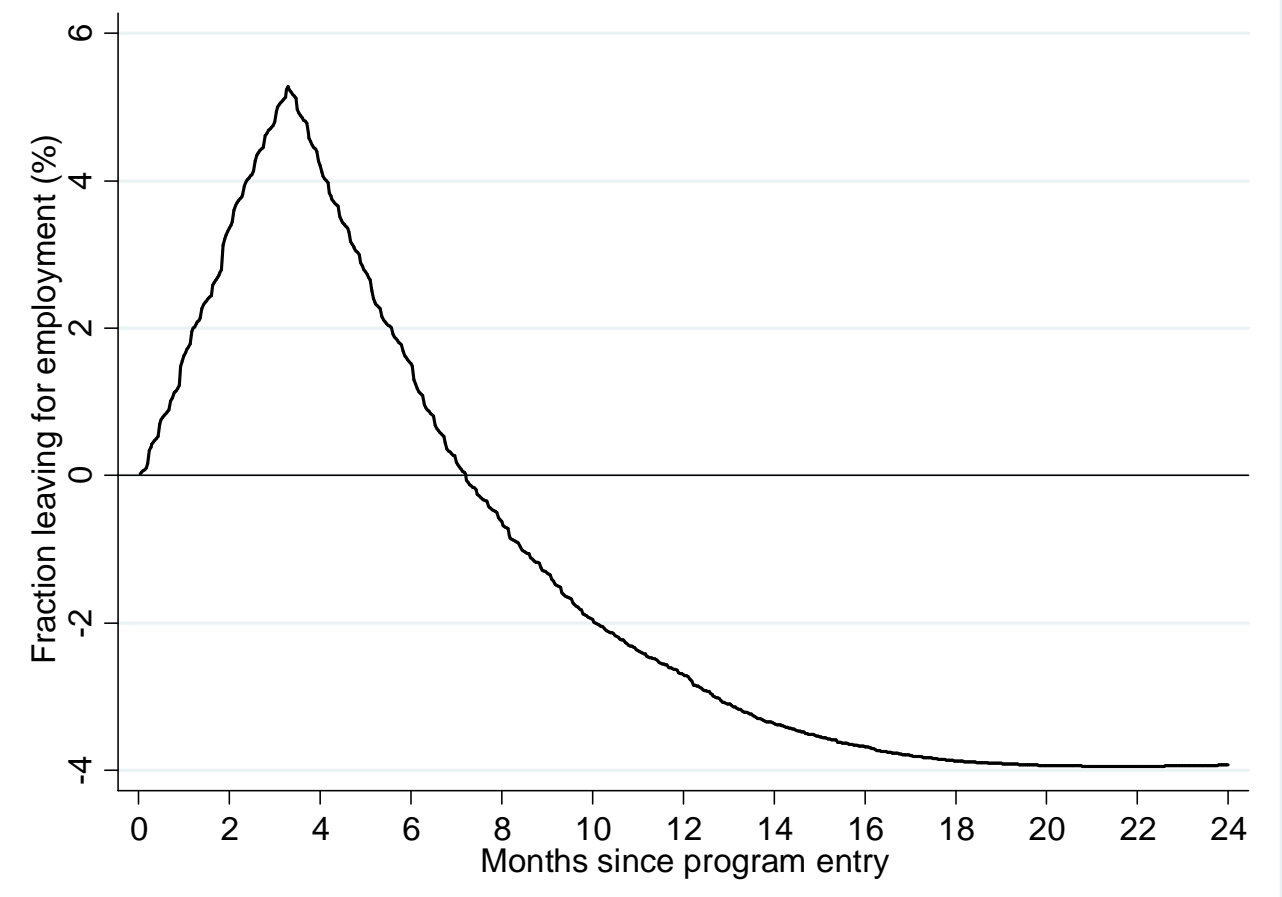

Figure 7: Effect of work practice relative to labor market training on the flow to jobs

Next we examine whether the effects of WP relative $L M T$ depend on the business cycle. We thus interact the treatment dummies with regional unemployment (regional $u$

\footnotetext{
${ }^{14}$ The difference in the survival functions integrates to the difference in mean duration. Therefore, $W P$-participation will reduce unemployment duration relative to $L M T$-participation when the two survival functions cross (at 218 days). Thus, $L M T$ only outperforms $W P$ with respect to unemployment duration with an extended evaluation window.
} 
denotes the regional unemployment rate at the month of program entry) to estimate differential relative program effects over the cycle. ${ }^{15}$ Column (2) presents estimates without any additional controls. These estimates indicate that higher unemployment contributes to a smaller difference in locking-in effects between the programs. The postprogram effect of $W P$ relative to $L M T$ also becomes more negative. All in all, this indicates that training is relatively more efficient in recession than in boom.

Note that even if the matched treatment and control group are comparable these estimates may be biased. One reason is that the quality of programs may vary systematically with unemployment. Another reason is that the population of eligible individuals may differ systematically between regions with high and low unemployment. We address these issues in two ways. First we introduce regional fixed effects. These regional fixed effects take care of any unobserved differences across regions influencing program effectiveness, provided that these are constant over time. Second, we allow the treatment effects to vary by a number of important characteristics like age, gender and level of education. This extension should further alleviate any problem associated with differences in the composition of the pool of unemployed individuals across high and low unemployment states.

This refined analysis is presented in columns (3)-(5). First we add year and region fixed effects and allow the general effect to vary by year and region (col. 3); then we also add fixed effects by program start dates and allow the treatment effects to vary by program start date (col. 4). Finally, we add individual characteristics on top of the other covariates, and the treatment effects are again allowed to vary by individual characteristics (col. 5). ${ }^{16}$ In our most elaborate model (see col. 5) we believe that it is highly unlikely that there are observed characteristics that may confound the correlation between the treatment effects and regional unemployment.

\footnotetext{
${ }^{15}$ Regional unemployment is measured at county level (län). It is defined as the number of individuals (aged 25-55) in each region registered as openly unemployed or as participants in a labor market program at the employment office relative to the total number of individuals (aged 25-55). The former is measured on the $15^{\text {th }}$ each month and the latter is measured once a year using official statistics from Statistics Sweden. Due to its small size we exclude the county of Gotland.

${ }^{16}$ The reference individual is a woman with less than upper-secondary education living in Stockholm in 1999. Regional unemployment rates are deviations from the mean, so that main effects can be interpreted as the mean effect at mean unemployment for the reference person defined above.
} 
Our preferred model is thus the one presented in column (5). According to these results, it is still the case that, on average, training outperforms work practice in the longer run, despite the fact that the lock-in effect of training is larger than that of work practice. Moreover, the lock-in effect of training is smaller in recession, and the postprogram effects also work in favor of training. The estimates in column (5) thus imply that training is relatively more efficient in recession than in boom, both because lock-in effects are less severe and because post-program effects are more beneficial when unemployment is high.

As argued above, it makes intuitive sense that the difference in locking-in effects between the programs is smaller in recession (high unemployment), since this is what one would expect if one thinks that the return to search is smaller when job-finding rates are low. We have no strong prior regarding the post-participation effects. But one may note that Lechner and Wunsch (2009) obtained analogous results.

What magnitudes are implied by the estimates in column (5)? To come up with a realistic evaluation point we calculated the difference in unemployment across time within region and then took the median of these differences. Over the studied time period (1999-2005) a median region experienced a difference between high and low unemployment states in the order of two percentage points. Thus we take an increase in unemployment by one percentage point to represent a recession, while a decrease of a percentage point represents a boom. Figure 8 illustrates the estimates by plotting the relative probability of leaving unemployment for employment across states of the business cycle. 


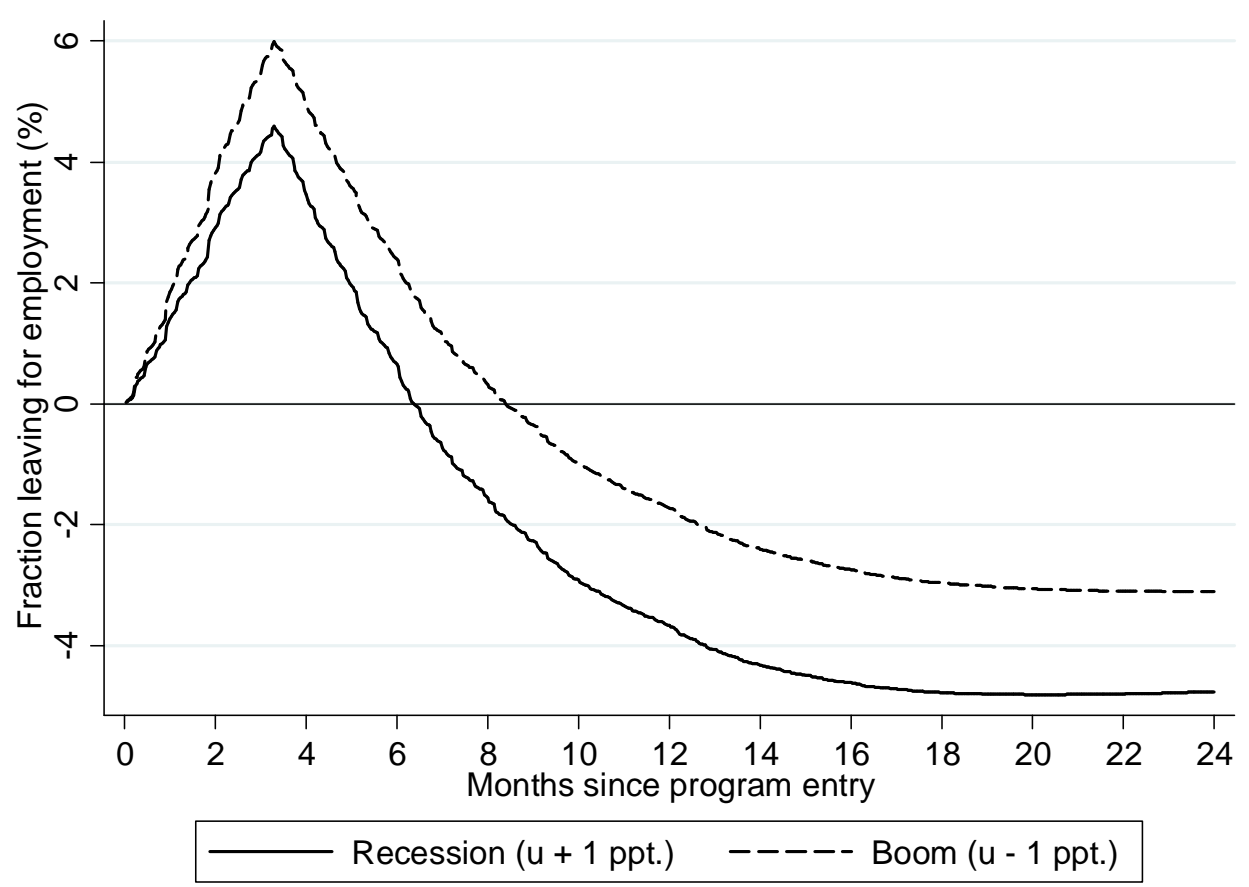

Figure 8: Effect of work practice relative to labor market training on the flow to jobs in boom and recession

Figure 8 shows that the lock-in effect of training is smaller in recession (the solid line is below the dashed line), that "break-even" occurs earlier in recession, and that the long-run treatment effect of training exceeds that of the practice program more in recession than in boom. Relative to work-practice, training has the long-run effect of increasing the probability of leaving for employment by 4.8 percentage points in a recession and 3.1 percentage points in a boom.

\section{$9 \quad$ Concluding remarks}

In this paper we have considered the case for expanding program activity in a recession. We find that there is reasonable case for doing so, which is tied to the varying size of the lock-in effect in boom and recession. Thus, if programs with relatively large lock-in effects should ever be used they should be used in recession. The reason is simply that the cost of forgoing search time is lower in recession. 
The above argument is primarily a case for expanding training in a recession. ALMPs affecting the returns to search (JSA and monitoring) should probably be reduced in recession.

The empirical evidence is extremely limited. Hitherto, Lechner and Wunsch (2009) is the only credible paper on this issue. They find that training appears to be more effective in a downturn. Nevertheless, this is only one study of a single program (training) for a single country (Germany).

To provide some more evidence we have compared the effects of an on-the-job training scheme to labor market training. On average (over the cycle), the on-the-job training scheme is associated with smaller (negative) lock-in effects and smaller (positive) long-run effects than labor market training. Our evidence also shows that the relative size of the lock-in effect is smaller in recession and that the long-run effects become less beneficial in a downturn. This suggests that it is relatively more efficient to use the labor market training scheme in recession than in boom.

In some respects our analysis is an improvement on the analysis by Lechner and Wunsch (2009), in others it is not. Despite the differences in the two approaches, our results are remarkably consistent with those of Lechner and Wunsch. Nevertheless, more evidence on this issue would be extremely welcome.

It is somewhat ironic that the clearest case for expanding program activity in recession pertains to training. A real problem is that training features relatively large fixed costs and capacity constraints. Therefore, the scale of this program is not easily adapted to the state of the business cycle.

Another caveat is that labor market training is likely to be more expensive than the on-the-job training scheme ("work practice"). According to Arbetsförmedlingen (2010b) the direct cost per participant was SEK 72,000 in 2008. Assuming that participants in labor market training (and work practice) would be paid a wage equal the wage on the $25^{\text {th }}$ percentile (SEK 20,900), and adjusting this number to take pay-roll taxes into account (pay-roll taxes roughly equal 40 percent) we conclude that labor market training would have to prolong employment duration by 2.5 months relative to 
work practice in order for the benefits to outweigh the costs. ${ }^{17}$ This is substantially larger than the effects on unemployment duration that we can observe during the evaluation window. Our estimates suggest that training reduces (truncated) unemployment duration over a two-year follow-up horizon by 16.6 days in recession and by 4.4 days in boom relative to work practice. This rough calculation thus implies that the effects of training would have to persist well beyond the evaluation window in order for the cost-benefit analysis to come out in favor of training. ${ }^{18}$

It seems to us that program effects in different phases of the cycle would be a very fruitful area for further research. Having said this, we are the first to recognize that this is a hard evaluation problem. Nevertheless, the prospects for conducting a well designed study increases over time along with the build-up of administrative registers covering a sufficient time span.

${ }^{17}$ To be more precise: $72,000 /(20900 \times 1.4) \approx 2.5$.

18 Obviously, there are many caveats to this calculation. Even during the follow-up horizon there are reasons to expect that we underestimate the benefits of training. First, we ignore the fact that training may reduce the probability of losing the job; the estimates in Forslund and Nordström Skans (2006) suggest that improved employment stability relative to the alternative programs that they considered. Second, we assume that participants in training receive the same wage upon employment as participants in work practice; if anything we would expect that contribute to higher wages relative to work practice. 


\section{References}

Ackum Agell, S. 1996. "Arbetslösas sökaktivitet." SOU 1996:34, Aktiv Arbetsmarknadspolitik, Expertbilaga till Arbetsmarknadspolitiska kommitténs betänkande, Fritzes, Stockholm.

Andersen, T.M. and M. Svarer. 2009. "State Dependent Unemployment Benefits." forthcoming Journal of Risk and Insurance.

Arbetsförmedlingen, 2010a. "Arbetsmarknadspolitiska program. Årsrapport 2009." Arbetsförmedlingen, Stockholm.

Arbetsförmedlingen. 2010b. "Arbetsmarknadsrapport 2010." Arbetsförmedlingen, Stockholm.

Card D., J. Kluve J, and A. Weber. 2009. "Active Labor Market Policy Evaluations: A Meta-Analysis." IZA Discussion Paper No. 4002.

De Luna, X., A. Forslund, and L. Liljeberg. 2008. "Effekter av yrkesinriktad arbetsmarknadsutbildning under perioden 2002-2004," IFAU Rapport 2008:1.

Ellwood, D. 1982. "Teenage unemployment: Permanent scars or temporary blemishes?" in R.B. Freeman and D.A. Wise (eds.), The Youth Labour Market Problem: Its Nature, Causes and Consequences. Chicago: University of Chicago Press.

Forslund, A. and O. Nordström Skans. 2006. "(Hur) hjälps ungdomar av arbetsmarknadspolitiska program för unga?" IFAU Rapport 2006:5.

Fredriksson, P. and B. Holmlund. 2001. "Optimal Unemployment Insurance in Search Equilibrium." Journal of Labor Economics, 19(2): 370-399.

Fredriksson, P. and B. Holmlund. 2006. "Optimal Unemployment Insurance Design: Time limits, Monitoring, or Workfare?" International Tax and Public Finance, 13(5): 565-585

Fredriksson, P. and P. Johansson. 2008. "Dynamic Treatment Assignment - The Consequences for Evaluations using Observational Data," Journal of Business \& Economics Statistics, 26(4): 435-445.

Groshen, E.L. and S. Potter 2003. Has Structural Change Contributed to a Jobless Recovery? Current Issues in Economics and Finance, 9(8): 1-8.

Johansson, K. 2001. "Do Labor Market Programs Affect Labor Market Participation?" Swedish Economic Policy Review, 8: 215-234.

Kluve J. 2010. "The Effectiveness of European Active Labor Market Policy." Labour Economics 17(6), 904-918.

Juhn, C., K.M. Murphy, and R. Topel. 1991. "Why Has the Natural Rate of Unemployment Increased over Time?" Brookings Papers on Economic Activity, 2:1991: 75-142.

Lechner, M. and C. Wunsch. 2009. "Are Training Programs More Effective When Unemployment Is High?" Journal of Labor Economics, 27(4): 653-692. 
van Ours, J. 2004. "The locking-in effect of subsidized jobs." Journal of Comparative Economics, 32(1): 37-55.

Mueller, A. 2010. "Separations, Sorting, and Cyclical Unemployment.", manuscript, IIES, Stockholm University.

Raaum, O, H. Torp, and T. Zhang. 2002. "Business Cycles and the Impact of Labour Market Programmes." Memorandum 14/2002, Department of Economics, University of Oslo.

Regnér, H. and E. Wadensjö. 1999. "Arbetsmarknadens funktionssätt i Sverige. En beskrivning baserad på nya intervjudata." SOFI, Stockholm University.

Schmieder, J, T. von Wachter and S Bender. 2009. "The Effects of Unemployment Insurance on Labor Supply and Search Outcomes: Regression Discontinuity Estimates from Germany." Discussion Paper 0910-08, Department of Economics, Columbia University.

Skedinger, P. 2010. "Hur fungerar arbetsmarknadspolitiken under olika konjunkturlägen?" Rapport till Finanspolitiska Rådet 2010/7.

Spinnewijn, J. 2010. "Training and Search during Unemployment." Manuscript, London School of Economics.

Wunsch, C. 2010. "Optimal Use of Labor Market Policies: The Role of Job Search Assistance." IZA Discussion Paper No. 4773. 